\title{
Metafizika bede \\ (Attila József, A. B. Šimić, Srečko Kosovel)
}

\author{
IsTVÁN LUKÁCS \\ Univerza Loránda Eötvösa, Filozofska fakulteta, ELTE BTK Szláv Filológiai Tánszék, \\ Múzeum krt.4/D, HU-1088 Budapest, slovenika@freemail.hu
}

SCN II/1 [2009], 119-128

\begin{abstract}
Ekspresionizem je bil najmočnejša smer srednjeevropskih avantgardnih literarnih gibanj. V madžarski, hrvaški in slovenski književnosti se je razvijal skoraj istočasno pod neposrednim nemškim vplivom, na osnovi koncepta »hibridne poetike«. Že to dejstvo bi upravičevalo primerjalno analizo književnosti tega prostora, kar pa se vse do zdaj ni zgodilo.
\end{abstract}

Expressionism was the most influential artistic movement among the Central-European Avantgarde. It developed at almost the same time as it did in Hungarian, Croatian, and Slovenian literature and was based on "hybrid-poetical construction" with German inspiration. This fact in itself might have formed a reason for analysis of the region's literatures; however, this has not yet been completed.

Ključne besede: ekspresionizem, avantgarda, pesmi o siromakih, madžarska književnost, Attila József, hrvaška književnost, Antun Branko Šimić, slovenska književnost, Srečko Kosovel

Key words: Expressionsm, Avantgarde, pauper-poems, Hungarian literature, Attila József, Croatian literature, Antun Branko Šimić, Slovenian literature, Srečko Kosovel

Attila József (1905-1937) je bil najpomembnejši pesnik madžarske književnosti med dvema vojnama preteklega stoletja. Njegovo pesništvo je sinteza najpomembnejših poetoloških teženj, od jasno prepoznavnih arhaičnih (narodnih/ljudskih) do modernističnih tokov in smeri. S svojim lirskim govorom in pesništvom je položil temelje nove objektivne lirike, ki pa se je razmahnila $\mathrm{v}$ povojnem obdobju. Objavil je sedem pesniških zbirk: Szépség koldusa (Berač lepote, 1922), Nem én kiáltok (Ne vpijem jaz, 1925), Nincsen apám, se anyám (Nimam očeta, ne matere, 1929), Döntsd a tökét, ne siránkozz (Ruši kapital, ne tarnaj, 1931), Külvárosi éj (Noč v predmestju, 1932), Medvetánc (Medvedji 
ples, 1934), Nagyon fáj (Zelo boli, 1936). Kot sin revne, proletarske družine v Budimpešti je $\mathrm{v}$ svojem pesništvu z elementarno močjo spregovoril tudi o bedi mestnih siromakov. Omagal je pod neprestanimi eksistencialnimi in duševnimi pritiski, ob koncu svojega življenja je zgubil tudi duševno ravnotežje. Ni našel izhoda iz lastne globoke krize, zato je skočil pod vlak.

V bogatem lirskem opusu Attile Józsefa zavzemajo pomembno mesto pesmi, ki so nastale v dokaj kratkem času, in sicer od leta 1924 do 1925, strokovna literatura pa jih uvršča med t. i. »szegényember-versek« (pesmi o siromakih). Pesmi o siromakih Attile Józsefa razlagajo na različne načine. Najbolj znan raziskovalec njegovega življenjskega dela Miklós Szabolcsi to pesnikovo obdobje imenuje »madžarsko narodno « (magyar népi). Te pesmi so enakovredne $\mathrm{z}$ ekspresionističnimi in grotesknimi, napisanimi $\mathrm{v}$ tem obdobju, toda njihov nastanek je odločilno vplival na madžarsko literarno narodnjaštvo in madžarsko folkloro (Szabolcsi 1977: 311-312). István Fried v svoji študiji, v kateri poskuša določiti mesto Attile Józsefa v srednjevzhodni Evropi, meni, da ne smemo iskati neposredne zveze med njegovimi relativno zgodnjimi pesmimi o siromakih in kasnejšimi baladami, ki so prepredene z »villonizmom« (Fried 1989: 212-222). Fried ugotavlja, da je v pesmih o siromakih Attile Józsefa čutiti vpliv narodnjaške lirike Józsefa Erdélyija (1896-1978), mogoče pa je dokazati tudi neposredno zvezo med priljubljenostjo znanstvenega in umetniškega uspeha, ki sta ga na začetku 20. stoletja dosegla v svetu najbolj znana madžarska skladatelja Béla Bartók (1881-1945) in Zoltán Kodály (1882-1967) na področju zbiranja ljudskih pesmi in s čimer sta $v$ sodobno glasbo vnesla veliko nemira. Vsekakor je treba omeniti tudi pozne pesmi najbolj znanega madžarskega lirika Endreja Adyja (1877-1919) o krucih, ki so - jezikovno in tematsko - prav tako blizu plebejskemu duhu. Avtor študije meni, da so Adyjeve pesmi o krucih »/.../ s pomočjo narodnega duha, blage arhaizacije in dialoških rešitev utrle pot pesmim o siromakih Attile Józsefa« (Fried 1989: 215). Ob razumevanju te problematike je treba vsekakor omeniti - o tem govori tudi Fried - da seveda obstajajo tudi drugačna razmišljanja o tem, npr. Imreta Borija, ki trdi, da pesmi Attile Józsefa o siromakih ne spadajo $\mathrm{v}$ krog tradicionalnega narodnjaštva, ampak gre pravzaprav za »ekspresionistične tragedije«, ki izvirajo iz ekspresionistične in konstruktivistične estetike. Analiza »poetičnega okolja« pesmi Attile Józsefa bi dokazala pravilnost Borijeve teze. Pesmi Antuna Branka Šimića o siromakih namreč v celoti potrjujejo Borijevo tezo. Béla N. Horváth v svoji monografiji o povezavi pesnika in folklore meni, da so njegove pesmi svojevrstno povzemanje težkih življenjskih izkušenj in spreminjanje lirskih zgledov v takratnem madžarskem pesništvu, torej gre za iskanje lastnega glasu. Siromak kot »glavni lik«, lirski subjekt teh pesmi je pravzaprav stilizacija raznih oblik obnašanja, v katerem se skozi brezosebno izraža kolektivno (N. Horváth 1992: 95).

Hrvaški ekspresionizem istovetijo s pesništvom A. B. Šimića. Njegova rodna Hercegovina je pustila globoke sledi v njegovem pesništvu. Svojo pesniško kariero je začel tako kot številni drugi literati v senci A. G. Matoša. V njegovem zgodnjem pesništvu je čutiti močan vpliv Matoševega simbolizma in impresionizma ter izrazito imitacijo Matoševih sonetov. Privrženost k temu t. i. 
harmoničnemu tipu lirike je bila kratkotrajna. Šimić je že v prvih samostojnih časopisih v ekspresionističnih programskih člankih predstavil tudi lastna, zrela stališča o novem lirskem govoru in novem lirskem konceptu. Empirijski svet je mogoče na osnovi pesniške izpovedi transponirati le skozi notranje vizije lirskega subjekta. Njegov protest proti dotedanjim razlagam lirskega razmišljanja velja tudi za pesniški jezik. Meni namreč, da jezik ni le predmet opisovanja, ampak je nujna alternativa razumevanja notranjih dogajanj. Prav zaradi tega je treba pesem osvoboditi jezikovnega okovja in jo podvreči novim pesniškim izkustvom. Lirski subjekt se nenehno bori za več harmonije - kar izhaja iz osnovnega koncepta in usmeritve ekspresionizma, toda nezmožnost tega in poraz kot končni izid se manifestira v vsaki pesniški zbirki. Postajališča te brezupne borbe tudi grafično odlično ovekovečuje $\mathrm{z}$ urejenimi stihi (brez ločil) - kar prav tako tvori posebno napetost in z njo posnema absurdnost sveta: kot da bi bilo mogoče ta svet razumeti le s pomočjo originalno konstruiranega, zapletenega, fabriciranega besedila. Šimić skuša mehanizem novega ritma pesmi razložiti z novo estetiko. Govori o notranjem utripanju, notranjem ritmu, ki ga ni mogoče več graditi s pomočjo za vse sprejemljivimi vezanimi oblikami, ampak s pomočjo monološkega in individualnega diskurza lirskega subjekta. $\mathrm{V}$ njegovem zrelem obdobju prav zaradi tega ne najdemo dveh enakih pesmi.

Pesniška zbirka Preobraženja iz leta 1920 pomeni novo poglavje v razvoju hrvaške lirike, in sicer zaradi svobodnejšega, bolj odprtega in bolj naravnega lirskega govora, z njo pa se konča tudi eno obdobje pesnikovega ustvarjanja. V časopisu Kritika (1922) je objavil sedem pesmi, ki jih je združil pod skupnim naslovom Siromasi. V ta ciklus je uvrstil naslednje pesmi: Siromasi, Sunce siromaha, Pogled siromaha, Ručak siromaha, Siromasi koji jedu od podne do podne, Siromahu, Post scriptum. Za samostojni ciklus so značilne nove pesniške težnje in tudi določen poetični preobrat, ki ima v literarnem ustvarjanju pesnika svojo »predzgodovino« in »pozgodovino«. Gre za dve vrsti besedil za biografsko in poetsko -, s pomočjo katerih lahko razložimo tudi nastanek Šimićevih pesmi o siromakih. Prozno besedilo Pjesma gladi je objavil leta 1916 v zagrebškem časopisu Novine. Gre pravzaprav za nekrolog, ki ga je Šimić napisal ob smrti prijatelja in rojaka Ilije Glavote. Pesnik se spominja skupnega otroštva, obuja boleče spomine na lepote domovine, na kratko predstavi življenjsko pot zgodaj preminulega prijatelja, ki je živel v revščini in siromaštvu. Šimić njegovo usodo interpretira simbolično: vsak Hrvat, ki želi usvojiti zahodno kulturo, se mora soočiti z lakoto in revščino. Zaključni del nekrologa je spremenil v svobodni verz: »Uništila ga je glad, okrutna, crna glad, jača od poezije, jača od života, jaka kao smrt. Njezina je pjesma gromorna i jaka, i mnogi je mora čuti, tko se hoće da dovine sunca kulture i znanja. Mnoge je već ona zaglušila, umorila svojim strašnim zviždukom. Ilija je Glavota jedan zvuk te pjesme, pjesme gladi, okrutne gladi ...« (Šimić 1960: 342-343). Za Šimića sta bila lakota in revščina prav tako vsakdanja izkušnja. Pesnik je v Zagreb prispel iz oddaljene Hercegovine in se ubadal z materialnimi težavami, medtem pa je skušal samotarsko ustvariti lasten literarni program. Po objavi pesmi o siromakih je v lastnem časopisu Književnik leta 1924 natisnil kratko besedilo z 
naslovom Pjesnici i prosjaci. Glede na to, da gre za kratko besedilo, ki je zelo pomembno za razumevanje njegovih pesmi o siromakih, ga navajam v celoti:

Poslao mi, valjda, neki mladić, da objavim ove stihove:

Dva su me prosjaka susrela:

Njihove ruke mole me.

Što da im dam?

Po licima im plove plave sjenke voćaka,

U očima: suncem nasmijani svijet,

Pod nogama: miris i cvijet.

Mogu li im išta ja još dati,

Kad sve im darova Bog?

Bogataši su izmislili da sunce jednako grije i bogata i siromašna. Ali ta je laž razumljivija nego kad jedan pjesnik tako dekorira svijet i veli da je prosjacima Bog sve darovao jer im »po licu plove plave sjenke voćaka, u očima: suncem nasmijani svijet, pod nogama: miris i cvijet«. Nije začudo što oni koji tako doživljuju siromaštvo, vele također: 'Mogu li im išta ja još dati?' I ja im često nemam šta dati, ali osjećam da sam i ja donekle kriv što ima uopće stvorova kojima se dariva milostinja. Bog i pjesnici ovakim frazama ne pomogoše im (Šimić 1960: 60).

Šimićeve pesmi o siromakih lahko preučujemo tudi na podlagi teh dveh publicističnih besedil. V prvem ob smrti prijatelja in tudi na osnovi lastne usode ugotavlja, da je lakota »jača od poezije, jača od života, jaka kao smrt«; s tem dobiva metafizične dimenzije in postane najpomembnejša tema pesništva samega. V njegovo prvo in edino zbirko (1920) niso bile uvrščene pesmi o revščini, pa čeprav je tudi sam imel jasno podobo o družbeni dimenziji te problematike, in sicer zato ker je bil poetski preobrat, ki je temeljil na svobodnem verzu, možen izključno le s postavitvijo lirskega subjekta v prvi plan. Opazovanje sveta iz te okrepljene in poudarjene pozicije jaza pa je verjetno povsem izključilo opazovanje sveta od zunaj, integracijo in vpletanje vsakodnevnih dogodkov v pesništvo. Po objavi svojih pesmi o siromakih (1922) v komentarju pesmi o beraču anonimnega čečkarja ugotavlja pravzaprav tisto, kar je v zadnji pesmi od sedmih pesmi o siromakih z naslovom Post scriptum tudi sam povzel in povedal: da pesništvo ne zna točno opisati neskončne bede. V svojih pesmih o siromakih, v katerih je "viden preobrat k družbeni tematiki in stvarnosti« (Milanja 2000: 49), se je lotil kar se da najbolj verodostojnega pesniškega opisa socialne bede, siromaštva in degradiranega vsakodnevnega življenja. V skladu s tem je njegov lirski govor enostaven, gol, pesniške oblike pa homogenizirane. Ivan Goran Kovačić je ob analizi tega obdobja Šimićevega pesništva ugotovil, da od tega trenutka vedno bolj pogosto uporablja rimo, njegove pesmi so vedno bolj popolne in zaprte, imajo manj prelomov, da bi bil ritem še bolj razigran, način izražanja bolj zbit in bolj elastičen, pesnik v nekaterih primeri pride do same meje poezije, toda nikoli ne preseže meja nerazumljivosti (Kovačić 1975: 209-217). V šestih pesmih o siromakih obravnava življenjske ravni in odnose v teh eksistencialnih stanjih: bližino smrti, vsakdanjik siromaštva, telo in hrano in na koncu nezmožnost kakršnega koli odpora. Sedma pesem je pravi zaključek, iskreno priznanje pesniškega poraza. 
Ko govorimo o Šimićevih pesmih o siromakih ponavadi omenjamo teh sedem pesmi in verjetno zato, ker so nastale istočasno in jih je tudi sam pesnik združil $\mathrm{v}$ celoto, objavil $\mathrm{v}$ istem časopisu. $\mathrm{S}$ tem pa tematika o siromakih $\mathrm{v}$ Šimićevem pesništvu ni sklenjena. To nedvomno potrjujejo tri pesmi, ki jih je objavil še v svojem življenju, in pesem v rokopisu: Okna na kućama siromaha, Napitnica, Konac, Ljubav siromaha. Od štirih pesmi, ki so ostale zunaj tematike o siromakih, lahko pesmi Okna na kućama siromaha, Ljubav siromaha nedvomno uvrstimo v samostojen ciklus, pesmi Napitnica, Konac pa resnično zaključujejo ta ciklus. Pesem Ljubav siromaha, ki je ostala v rokopisu, pa je pravzaprav ljubezenska pesem, toda na podlagi naslova jo je mogoče vendarle uvrstiti v tematiko o siromakih. Pesem Napitnica je izrazito pravilno sestavljena vinska pesem, zdravica: prve tri kitice so tradicionalno sestavljene iz dveh simetričnih osmercev in enega šesterca. Zadnjo kitico tvorijo trije simetrični osmerci in en dvozložni verz. To je vsekakor enkratna pesem v vsej Šimićevi liriki, v njegovem zrelem obdobju ni podobne. Glede na tematiko vsekakor sodi med pesmi o siromakih. Pesem Post scriptum v duhu svobodnega verza na prvi pogled zaključuje ciklus pesmi o siromakih, toda Napitnica s svojim počasnim, ironičnim tonom in močno vezano obliko odpira nove perspektive. Prava sklepna pesem tega ciklusa pa je pesem Konac. Pesnik se je spet vrnil $\mathrm{k}$ resnejši obravnavi te teme in jo s svojstveno groteskno opozicijo dvignil na univerzalno raven. Vse to doseže s pesniško-tehničnimi postopki in jezikom, ki pa je svojo zrelo podobo dobil v zbirki Preobraženja.

Pesmi o siromakih A. B. Šimića na prvi pogled odpirajo novo poglavje v njegovem pesniškem razvoju, toda po soočenju z možnostmi, ovirami in mejami poetskega preobrata pesnik ne more brez lastnega, izvirnega in priljubljenega pesniškega instrumentarija. V genezi pesmi o siromakih ne smemo iskati le zunanjih inspiracij (npr. estetika in poetika ekspresionizma) - »pad u stvarnost«, lastno doživetje in beda so igrali odločilno vlogo pri ustvarjanju verzov, prav tako kot tudi pri madžarskem pesniku Attili Józsefu, točno v istem času - neodvisno drug od drugega.

Tako kot pesništva Antuna Branka Šimića tudi Kosovelove lirike ni mogoče razvrstiti v zaporedne faze razvoja kot so impresionizem, ekspresionizem, konstruktivizem, saj se njegove »pesmi takšnemu strogo teleološkem pogledu izmikajo « (Kos 1997: 152). Odgovor na to je treba iskati v preprostem dejstvu, da je večji del njegovega življenjskega dela nastal v kratkem času med leti 1923 in 1926. Anton Ocvirk, urednik kritične izdaje Kosovelovega življenjskega dela, je prav zaradi tega Kosovelovo liriko razdelil $v$ štiri motivno-tematske skupine: 1. impresionistični kraški cikel, 2. refleksivni soneti, 3. socialnoborbene in idejne pesmi, 4. osebno-izpovedna lirika (Kosovel 1864: 428). Ta razdelitev na motivno-tematske skupine, vključno s kasneje objavljenimi Integrali (1967), je določila smer interpretacije Kosovelovega življenjskega dela (Zadravec 1986). Novejše raziskave Kosovelove lirike poskušajo življenjsko delo preusmeriti in ga imajo za celostno, sintetično celoto, ki je nastala na osnovi logike »hibridne poetike« (Juvan 2003: 106-122). 
Socialne, humanistične, krščanske, proletkultovske, delavske, revolucionarne pesmi Kosovelovega življenjskega dela, ki so jih vedno interpretirali v aktualnem političnem kontekstu, nedvomno pričajo o tem, da so etične vrednote dvignjene nad estetske vrednote (Juvan 2003: 111). Kar seveda ne pomeni, da nova literarna dovzetnost do stvarnosti (!) odpravi, reducira ali degradira literarno estetiko. Gledano iz zornega kota poetike modernizma gre za to, da približevanje poetiki nove stvarnosti prestrukturira celoten lirski jezik, občasno oplazi njegove meje ter uveljavlja in sledi konstrukcijskim načelom, ki kažejo v smeri objektivne lirike.

Boris A. Novak v študiji Kosovel, velik pesnik in slab verzifikator piše tudi o pesnikovih rimah (Novak 2005: 7-17). V nekaterih Kosovelovih besedilih (Vas za bori, Ne, jaz nočem še umreti, Daj mi, Bog, Žene s polja) zasledimo ponavljanje besed kot najbolj preprosto vrsto rime:

Voklepu zelenih borovih rok

bela, zaprašena vas,

poldremajoča vas,

kot ptica $v$ varnem gnezdu rok.

(Vas za bori)

V smislu strožje, pravilne poetike bi to lahko bila napaka, toda dosledno ponavljanje postane sistem in poetično sprejemljivo. Boris A. Novak o tem piše: »Ponovljena napaka ni več napaka; je že sistem. Na začetku svoje pesniške avanture je Kosovel intuitivno sledil prav tej umetniški strategiji: ponoviti napako! Iz formalne napake narediti umetniško resnico!« (Novak 2005: 7). Boris A. Novak je z vidika poetične funkcionalnosti natančno razkril Kosovelovo logiko »zavestnega in plodnega postopka«. Isti depoetizacijski postopek srečamo tudi v pravilnih pesmih o siromakih Attile Józsefa. Postopek depoetizacije je v nekaterih pesmih prisoten le delno in ne dosledno skozi celo pesem, so pa tudi take pesmi, v katerih je ponavljajoča se rima shema za organizacijo besedila (Szegényember szeretője, Szegényember balladája):

Szegényember balladája

- Szegényember, hogy adod a bölcsőt?

- Csöpp a gyerek, hogy adnám a bölcsőt?

- Király vagyok, bírok nagy erővel,

Ha nem adod, elveszem erővel.

Szegényember, hejh, csak egyet szólna -

A király már katonákért szólna.

De a bölcsőt a tóba hajítja,

Csöpp gyerekét utána hajítja.

Szegényember sír-rí a börtönben.

Szegényember nevet a börtönben.

Nincs a gyerek már a rossz világban,

Jobb sora lesz, hajh, vizi-világban!

\section{Balada o siromaku}

- Siromak, ali mi prodaš zibelko?

- Moj otrok potrebuje zibelko.

- Kralj sem, obdarjen z veliko močjo,

Če je ne daš, jo vzamem z močjo.

Ko bi siromak milost prosil Kralj bi hitro vojsko prosil.

Zibelko on v jezero vrže,

Za njo šibkega otroka vrže.

Siromak joka v zaporu.

Siromak smeje se v zaporu.

Otrok ni več na hudem svetu.

Naj bo, hoj, v vodnem svetu. 
Tematika o siromakih se pri Antunu Branku Šimiću v glavnem realizira v svobodnem verzu, toda tudi pri njem zasledimo ponavljanje besed na koncu besedila kot najpreprostejšo obliko rime:

Siromasi nestalno lebde

između života $i$ smrti

i svaki čas može da pretegne

nevidljivi uteg smrti.

(Siromasi)

Pesem z naslovom Napitnica je izjema tudi v tem pogledu, kot sem to že prej omenil, saj je v celoti pravilna. Ob pravilnosti števila zlogov je ponavljanje besednih zvez in besed $\mathrm{v}$ prvih vrsticah prvih treh pravilnih verzov prav tako pomemben element organizacije in strukturiranja besedila:

Napitnica

Mi smo siti. Mi smo siti.

A za druge nek se stara

Onaj tko ih stvara!

Sad hajdemo piti, piti!

Plod sve tuđe muke

dolazi u naše ruke!

Opijmo se, opijmo se!

Za bol drugih nijemi,

Za krik drugih gluhi!

I bez nas se zemlja vrti!

Tko se muči i tko trpi

sam će naći mir u smrti!

Pijmo!

V omenjeni študiji Borisa A. Novaka ob nepravilnosti, »napačnosti« zasledimo še eno ugotovitev, ki je novost v strokovni literaturi o Kosovelu in ki je morda odločilna glede pozicioniranja Kosovelovih socialnih, humanističnih, krščanskih, proletkultovskih, delavskih, revolucionarnih pesmi:

Mnoge Kosovelove zgodnje pesmi so v zvrstnem in formalnem smislu modernizirane balade. Zanimivo je, da z oznako Balada Kosovel naslovi drobno in preprosto pesem, ki je ena izmed njegovih najbolj priljubljenih /.../V tej pesmi Kosovel kombinira pripovedne in lirske prvine. Ta zvrstni vidik in tragični konec sta najbrž razloga, zakaj je pesnik naslovil to besedilo kot Balado. Po drugi strani najdemo pri Kosovelu mnoge pesmi, kjer - zavestno in podzavestno - poleg zvrstnih in sporočilnih razsežnosti upošteva tudi formalne značilnosti balade, kakor jo poznamo iz slovenskega ljudskega slovstva (Novak 2005: 13).

Toda pesniški instrumentarij, ki ga poznamo iz ljudskih pesmi, se ne pojavlja le $\mathrm{v}$ baladah in baladam podobnim pesmih, ampak tudi $\mathrm{v}$ številnih drugih. Sklepni verzi kitic deskriptivne, zelo kratke in enostavne pesmi z naslovom Jesen so skoraj obvezni, skoraj nujni refreni v ljudski pesmi (»Sivo je zgodnje jutro«). Ponavljanje zadnje besede prejšnje vrstice v velelni obliki v sklepnem 
verzu kitice v ljubezenski pesmi Romanca je prav tako kliše, ki ga poznamo iz ljudske pesmi (oj sam, oj srca, oj kam?). V drugi kitici kratke pesmi Melanholija gladu, ki sodi med pesmi s socialno tematiko, sta prav tako prisotna za ljudske pesmi značilno paralelno konstruiranje s ponavljanjem in monotonija rim:

Padaj, padaj, hladni dež,

hladni dež jesenski,

padaj, padaj, tihi dež,

padaj na gomile.

Iz zgoraj navedenega je razvidno, da v Kosovelovi liriki najdemo identične ali sorodne zvrsti (balade), identične ali skoraj identične poetične elemente, vzete iz ljudskega slovstva, kot v pesmih o siromakih Attile Józsefa in A. B. Šimića.

Franc Zadravec o Kosovelovih pesmih Večerja, Žene s polja, Starka za vasjo, Melanholija gladu, ki izrazito sodijo v tematiko o siromakih, piše, da je pesnik pri predstavitvi socialnorealistične vsebine uporabil sredstvo impresionističnega punktualizma, torej »pesem noče izpovedati predvsem pesnikovega osebnega občutja, ampak le punktualistično naslika delček stvarnega življenja kraške vasi« (Zadravec 1986: 51). Še zlasti po primerjavi s sorodnimi pesmimi s socialno tematiko A. B. Šimića (Ručak siromaha, Siromasi koji jedu od podne do podne) postane jasno, da $\mathrm{v}$ tem primeru ne gre za impresionistični punktualizem, ampak za ekspresionizem značilno tehniko montaže, predhodnico objektivne lirike, ki kaže v smeri sodobne vizualnosti (film). Torej sploh ni slučajno, da se ta novi način pesniškega izražanja pri Kosovelu najbolj izrazito pojavlja prav v pesmih s socialno tematiko. V duhu »hibridne poetike« se je v slovenski književnosti odprl nov kanal, ki pelje do objektivne lirike, prav tako kot $\mathrm{v}$ hrvaškem in madžarskem pesništvu. Tehnika montaže, ki se je razvila $\mathrm{v}$ pesmih o siromakih, prav zaradi tega igra pomembno vlogo in zavzema svoje mesto v zgodovini lirike.

Pojmovno novo pozicioniranje socialnih, humanističnih, krščanskih, proletkultovskih, delavskih in revolucionarnih pesmi, ki jih je slovenska literarna zgodovina v Kosovelovem življenjskem delu poudarila zaradi tematskega vidika, bo odpravilo ideološko polje, ki je omejilo interpretacijske možnosti teh besedil. Ponuja se možnost sprejetja terminus tehnikusa pesmi o siromakih, kakor sta pesmi s sorodno tematiko imenovala madžarski pesnik Attila Józsefa in hrvaški pesnik Antun Branko Šimić. Na podlagi pojmovno novega pozicioniranja teh pesmi in poznavanja besedil dveh pesnikov z identično tematiko se jasno kaže, da se k proletkultovskim besedilom z močno ideološko dispozicijo pridružujejo novejša besedila, kot so Kraška vas I, II, III, Žene s polja, Večerja, Predkosilni sonet, Iz cikla: Peto nadstropje, Mati, poljubljam tvoj kruh, Obrazi brez sanj, Pesem ponižanih, Bedno življenje I, II, III, IV, Melanholija gladu, Starka za vasjo, Trudni od dela. Njihova skupna značilnost je, da tako kot $\mathrm{v}$ pesmih o siromakih Attile Józsefa in A. B. Šimića, ki so nastale v glavnem v istem času, sploh ni prisotna politika in ideologija ali pa le v skromni meri. Drugače rečeno: najpomembnejši pesniki madžarskega, hrvaškega in slovenskega ekspresionizma so v istem času spoznali, da je beda metafizične narave 
in je nad ideologijo, ter so jo s točnimi sredstvi tehnike montaže detektirali na depoetiziran način.

\section{LITERATURA}

István FRIED, 1989: József Attila kelet-közép-európai helye. Utak és tévutak KeletKözép-Európa irodalmaiban. Budapest: Magvető Könyvkiadó. 212-222.

Béla N. HORVÁTH, 1992: »Egy kis márványból rak falut ...«. József Attila és a folklór. Budapest: Babits Kiadó.

Marko JUVAN, 2003: Srečko Kosovel med moderno, avantgardo in modernizmom. Literarni izzivi. Maribor: SAZU. Univerza Maribor - Pedagoška fakulteta. 106-122.

Matevž KOS, 1997: Kako brati Kosovela. Srečko Kosovel: Izbrane pesmi. Ljubljana: Založba Mladinska knjiga. 129-165.

Srečko KOSOVEL, 1964: Zbrano delo I. (2. izdaja). Ljubljana: Državna založba Slovenije.

Ivan Goran KOVAČIĆ, 1975: Pjesnik tijela i siromaha. Novele, pjesme, eseji, kritike i feljtoni. Zagreb: Zora. Matica hrvatska. (Pet stoljeća hrvatske književnosti 135).

Cvjetko MILANJA, 2000: Pjesništvo hrvatskog ekspresionizma. Zagreb: Matica hrvatska.

Boris A. NOVAK, 2005: Kosovel, velik pesnik in slab verzifikator. Primerjalna književnost (posebna številka), 7-17.

Miklós SZABOLCSI, 1977: Érik a fény. József Attila élete és pályája 1923-1927. Budapest: Akadémiai Kiadó. 311-312.

Antun Branko ŠIMIĆ, 1960: Sabrana djela. Knjiga III. Proza II. Zagreb: Znanje.

Franc ZADRAVEC, 1986: Srečko Kosovel (1904-1926). Koper, Trst: Založba Lipa in Založništvo tržaškega tiska.

\section{METAPHYSIC OF MISERY (ATTILA JÓZSEF, A. B. ŠIMIĆ, SREČKO KOSOVEL)}

In my study, I emphasize three notable poets who are partly expressionists and who were born in the early twentieth century. I focusing on poems having a specific agenda - poverty - which I designate as 'pauper-poems' according to Attila József in Hungarian Literary history. The Hungarian poet Attila József wrote such poems between 1924 and 1925. Hungarian Literary history hs e not found any unified explanation for the literary origins of these poems, since these were sometimes connected with art-folklore poetry, and sometimes with the ballads of Villon, but it is also reasonable to see them as expressionist tragedies based on a constructionist aesthetic. In 1922, the Croatian, Antun Branko Šimić, spontaneously brought out several pauper-poems, which tend to 
show a shift to the representative volume of the Avantgarde: an intensive turn to reality. Throughout the short poetic career of the Slovenian, Srečko Kosovel, he created his own pauper-poems, simultaneously with the other two poets. The writing of Slovenian literary history is mostly realistic, discoursing on social issues such as the working class. Literary-critical articles have paid little attention to the fact that, as in the case of this two poets, the concrete agenda is combined with a visible poetical shift: the culmination of the balladic tone, the gradual monotony of lyrical language and the decline of the folk-song tone. 